\title{
Exploring an integrated spatially model for land-use scenarios simulation in a metropolitan region
}

\author{
Hashem Dadashpoor ${ }^{1}$ (D) $\cdot$ Hossein Panahi ${ }^{1}$ \\ Received: 15 August 2019 / Accepted: 8 January 2021 \\ (c) The Author(s), under exclusive licence to Springer Nature B.V. part of Springer Nature 2021
}

\begin{abstract}
Spatial simulation of land-use change scenarios in metropolitan areas is essential for analyzing both the causes and consequences of various future scenarios and is also valuable for land-use planning and management. However, current simulation models primarily focus on spatial and rarely on quantitative driving factors. This article aims to simulate future scenarios of land-use changes in the Tehran metropolitan region (TMR) by combining different models to fill this gap. Thus, in the first step, land-use changes were analyzed in the period 1985,2000 , and 2015 . Then, by identifying the impact of driving factors and land-use transition potentials with Logistic regression (LR), land-use changes were allocated using the Cellular Automata (CA) method. Finally, with the validation of the model, four scenarios of the current trend(CT), socioeconomic growth(SEG), ecologicaloriented(EO), and integrated development(ID) were suggested with the combination of the System Dynamic (SD) model. The results show that the trend of land-use changes in TMR has led to the destruction of grassland, agricultural, and uncultivated lands and the continuation of this trend will increase the damage of built-up areas on valuable natural and ecological resources. In this way, proximity to roads, distance from built-up areas, and natural factors had the greatest impact on changes. Based on future scenarios in 2030, the change in the SEG-scenario shows a rapid increase in built-up areas $\left(2858 \mathrm{~km}^{2)}\right.$ and encroachment on agricultural lands $\left(2171 \mathrm{~km}^{2)}\right.$. In the EO-scenario, destruction of grassland and agricultural lands and the growth of built-up areas will be limited, while CT-scenario leads to the high growth of built-up areas along with destructive impacts on natural and open spaces. In the ID-scenario, the built-up areas and grasslands will increase to $2808 \mathrm{~km}^{2}$ and $7438 \mathrm{~km}^{2}$, respectively. Accordingly, policy-makers can use simulation of different scenarios to mitigate probable consequences of land-use changes in the metropolitan regions.
\end{abstract}

Keywords Land-use changes - Spatial simulation - Socioeconomic - Climate changes · Integrated development $\cdot$ Trend scenarios $\cdot$ System dynamics $\cdot$ Metropolitan regions

Hashem Dadashpoor

h-dadashpoor@modares.ac.ir

Hossein Panahi

hpanahi@modares.ac.ir

1 Urban and Regional Planning Department, Faculty of Arts and Architecture, Tarbiat Modares University, Tehran, Iran 


\section{Introduction}

The rapid growth of population, economic development, and subsequent increase in urbanization cause extensive influences on environmental resources and valuable agricultural lands through transforming them into built-up areas (Han et al. 2015). These influences take place in three local, regional, and global levels including changes in natural resources (Rounsevell et al. 2006), the ecosystem (Arunyawat and Shrestha 2018), agricultural land (Verburg et al. 2002), soil performance (Moein et al., 2018), environment quality of settlements (Al-shalabi et al 2013), and regional spatial structure (Henríquez-Dole et al., 2018). Over the last decades, these influences have destroyed the environment in metropolitan regions, especially in developing countries, due to changes in the land use of the surrounding areas (Hosseinali et al. 2013; Q. Wu et al. 2006; Dadashpoor et al. 2019a).

Sprawl growth and development of the metropolitan regions have transformed the agricultural lands, gardens, open spaces, and grasslands into the newly built-up areas in the suburbs (Arsanjani et al. 2011). Most of these land-use changes occur with complexity and high speed. Along with these massive changes, the lack of proper planning processes leads to the destruction of agricultural and green lands, increased environmental pollution, and ecological damages. On the other hand, the lack of a proper understanding of the environmental consequences of land-use changes poses a threat to the balance of sustainable development (Senes and Toccolini, 1998; Dadashpoor et al. 2019a, b; Dadashpoor and Ahani 2021). The continuation of such a trend will make it necessary to draw an optimal pattern for metropolitan regions according to different scenarios appropriate to the natural, economic, and social environment.

Currently, land-use/cover change, and its impacts have become a major area of the debate in environmental changes and sustainable development (Sun et al. 2016). The trend of land-use changes is a dynamic and complicated process resulting from the interaction of natural, social, and economic factors (Han et al. 2015). A comprehensive understanding of these dynamics can help identify the trend of past changes and predict future changes. Simulation is used as an efficient way to understand these changes (Verburg et al. 2002). In recent years, several studies have addressed the modeling of land-use changes in different regions, and have provided useful achievements for sustainable development. Thus, developing scenarios based on effective and efficient land-use models (Deng and Li 2016) can determine the optimal spatial patterns of regional land use (X. Sun et al. 2012; Zarei et al. 2016) aiming to preserve the ecology and environment (Verburg et al. 2006). In the meantime, Geographical Information System (GIS) and Remote Sensing (RS), with advanced capabilities in analyzing and processing spatial data, are recognized as effective tools for analyzing past changes and modeling future potential changes and a combination of these two are an appropriate framework to obtain, store, process, analyze and finally modeling the data.

Scenario simulation has been previously adopted in many studies in land-use changes (Han et al. 2015; Li and He 2008; X. Liu et al. 2017; Rounsevell et al. 2006). Some studies have investigated the trend/historical scenario (Abuelaish and Olmedo 2016; Bihamta et al. 2015). Some other studies have focused on the ecology, environment, landscape, and agriculture scenarios (M. Liu et al. 2011; P. Sun et al. 2016). However, few studies have used integrated development scenarios to explain the land-use change (X. Liu et al. 2017). In the meantime, due to the scale of studies and different characteristics of case studies, scholars have adopted various spatial driving factors (Arsanjani et al. 2011), while quantitative driving factors such as gross domestic product (GDP) and population changes are rarely 
studied. On the other hand, various models have been developed to conduct different scenarios. These models are mainly Cellular Automata (CA) based (Berberoğlu at al. 2016) such as CA-Markov(Al-sharif and Pradhan 2014), CA-Logistic Regression (Arsanjani et al. 2011), ANN_CA(X. Yang et al. 2016), CLUE-S (Verburg et al. 2002) and SLEUTH (Al-shalabi et al. 2013). Although these models are effective in spatial simulation, there is a lack in combining the quantitative data in the simulation process. Therefore considering various driving factors with different kinds of data requires an integrated model that simulates land-use changes in both spatial and quantitative dimensions. In this research, with a focus on socioeconomic and climate change factors, SD as a quantitative model in the prediction of land-use demand in different scenarios is combined with LR and CA models.

This study's focus is on metropolitan regions where land-use changes are perceptible and can have significant effects on urbanization (Dadashpoor et al. 2019b), fragmentation of natural resources, and climate changes (Azadi et al. 2016). Tehran Metropolitan Region (TMR), adopted as a case study, has witnessed a widespread expansion of urban areas over the past decades (Dadashpoor and Nateghi 2017), destroying agricultural lands and enormous environmental problems in the region (Arsanjani at al. 2012). Thus, it is necessary to understand the past trend of the changes and its main driving factors, as well as providing an integrated scenario for optimal planning and policy of land use. Furthermore, metropolitan areas are complex systems that simultaneously influence the spatial and quantitative factors in their changes and affect their various feedback processes. Thus, integrated modeling and combining of spatial and quantitative factors are needed into an integrated model. In this paper, with emphasis on socioeconomic and climate change driving factors, the combination of the System Dynamics (SD) as a quantitative model and Logistic Regression (LR) and Cellular Automata (CA) models in the spatialization of the scenarios is proposed as an integrated spatially model for future land-use change. By changing the impact level in each of the indicators (as a driving factor of land-use change in the modeling process), probable future patterns of land use can be obtained according to environmental, economic, social, and integrated perspectives. With these in mind, this study aims to identify the future patterns of land-use changes in four scenarios: current trend(CT), socioeconomic growth(SEG), ecological-oriented(EO), and integrated development(ID) in TMR, by combining the quantitative models (SD) and spatial models (LR and CA).

\section{Data and material}

\subsection{Study area}

TMR, in the northern region of Iran, includes two provinces of Alborz and Tehran (Fig. 1). This region is the most populated and most important social, economic, cultural, and political center in Iran (Dadashpoor and Alidadi 2017) with an area of over $18,813 \mathrm{~km}^{2}$ extended between the Alborz Mountains in the north and desert areas in the south. In the northern regions of the study area, due to the Alborz mountain range, they have a high slope and are mainly located in grasslands, and the southern regions of the lands are suitable for agriculture. The climate of the northern regions is mountainous and has a semi-humid climate. The middle regions are the semiarid and southern regions with a dry climate. The water bodies of the region include three main rivers of Karaj, Shur, and Jajrood which provide the needed water of the region. 


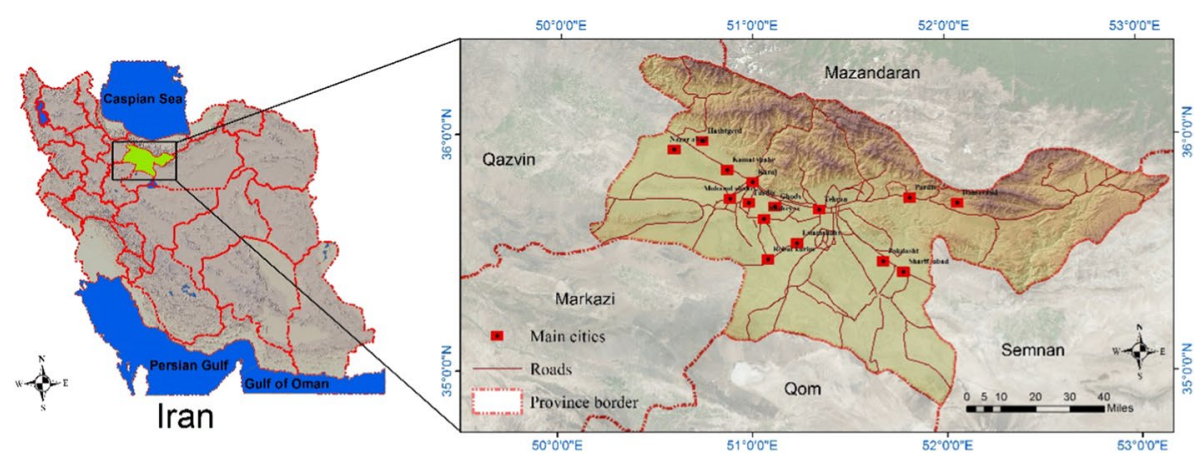

Fig. 1 Location of TMR in Iran

The population in TMR in 1976 and 1996 was 5,245,591 and 10,343,965, respectively. In the latest Iran census in 2016, the region's population reached 15,980,037 people (Statistical Center of Iran 2016). The largest population in the metropolitan region belongs to Tehran, with 8,693,706 people, and Karaj with 1,592,492 people.

In the economic activity, TMR generates more than 25 percent of GDP, and most of Iran's major industries are concentrated in this region, and the main focus of Iran's high services is in this region. In the past decades, TMR has experienced high urbanization and, consequently, major land-use changes due to the natural growth of population, rural-urban migration, development of large industries, and population recruitment, and political and administrative centrality of the country (Dadashpoor and Nateghi 2017). These changes threaten valuable agricultural lands in the south, natural resources in the north, and the environment in the west and east of Tehran, and have witnessed a steady decline in green and open lands in favor of built-up areas. In TMR, especially around Tehran and Karaj, the growth of built-up lands and population density in the south, dry and salt marshlands in the north, topography, and soil erosion are three significant restrictions for valuable lands.

\subsubsection{Spatial data}

Topography maps were obtained from the National Cartographic Center of Iran, and environmental data were collected from Tehran Spatial Planning Document. To draw the spatial-temporal patterns of land use in the studied area, remote sensing archives' data were employed. Related multispectral images of Landsat 5 (TM) for 1985, Landsat 7 (ETM+) for 2000, and Landsat 8 (OLI) for 2015 , with $30 \times 30 \mathrm{~m}$ spatial resolution, were obtained for the TMR. The region includes six types of land use: built-up lands, agricultural and garden lands, urban green and open spaces, grasslands, unused lands, and water bodies. After extracting the land use by the support vector machine (SVM), the results were validated. To this end, 417 points were selected randomly on images and the use of these points was determined through field observations, Google Earth images, and topography maps of the National Cartographic Center of Iran. The overall accuracy reached 86, 90, and 88 , and the Kappa coefficient was used for accuracy assessment of the classified images, which was $85,86,85 \%$ for 1985,2000 , and 2015, respectively, and in comparison with other studies (Lamine et al. 2017; Puertas et al. 2014), indicating the high accuracy of the produced maps. Based on the land-use maps for 1985, 2000, and 2015, land-use changes in 
each period are specified. These changes are indicated by the binary map 0 and 1 , in such a way that 1 indicates the change of this use and zero indicates no change.

A set of driving factors were selected based on the data collected through interview with several experts in this field as well as the information provided in scientific studies on the studied area (Arsanjani et al. 2012; Shafizadeh-Moghadam et al. 2017a, b; Zarei at al. 2016). The selection of the factors was based on specialized knowledge, methodological orientation, and access to data. These data include topographic factors, height, and slope to take the effects of geographical, environmental, and natural factors into consideration in the land-use change process. The existing pixels in these factors were weighed against the actual values of height and slope. The distance factor includes the distance to existing built-up areas, distance to agricultural lands, distance to existing unused lands, distance to grasslands, distance to population centers, distance to a surface water body, distance to main roads, and distance to the railway (Fig. 2).

The mentioned driving factors were valued according to the distance of each pixel to the existing feature (Fig. 2). These factors were normalized and acquired numbers between 0 and 1 (Sakieh et al. 2015). They were then converted to a grid network, with the grid equal to that in the land-use maps. In these factors, each grid has a value that indicates the value of that grid in the given factor. The factors were generated from the existing raw data, using ArcGIS software (Verburg et al. 2002).

\subsubsection{Quantitative data}

Demographic changes in the TMR were examined to measure the influence coefficient of this variable on land-use changes from 1995 to 2016. In 1996, TMR included 10,343,965 inhabitants, which increased to $13,422,366$ in 2006 . In this period, the annual population growth rate of the region was 2.64. In 2016, the population grew to 15,980,037, with an annual growth rate of 1.75 compared to 2006 (Statistical Center of Iran 2016). Accordingly, for this study, the average annual growth rate of the population was taken as the annual growth rate of the

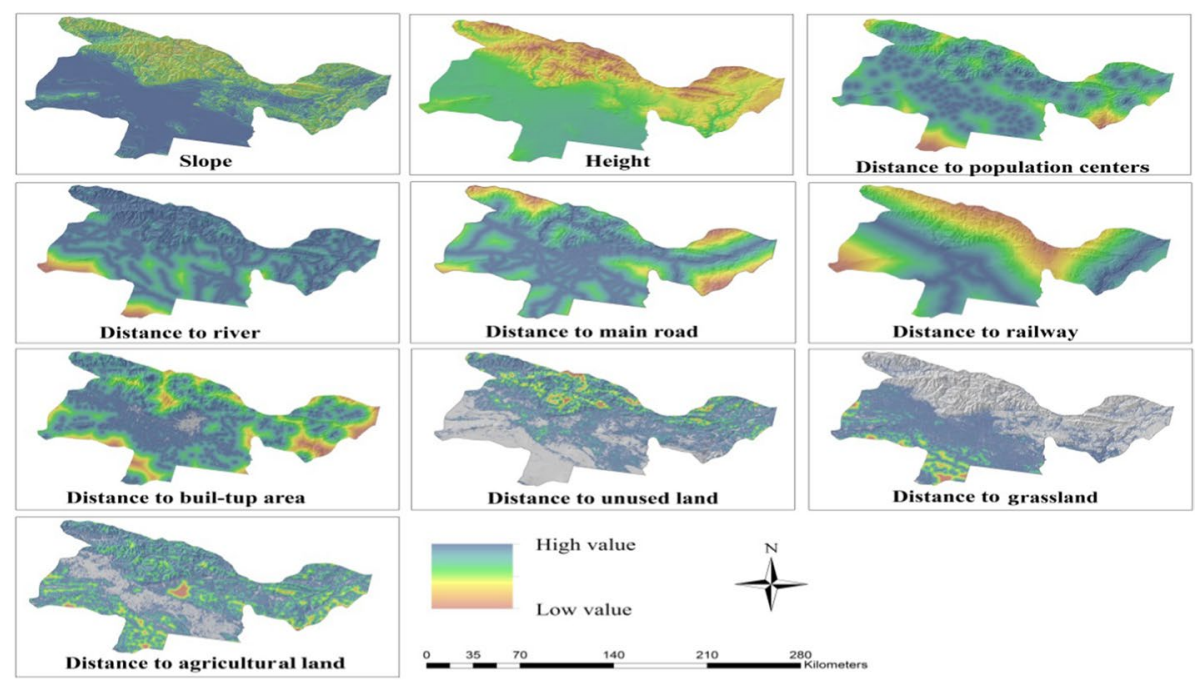

Fig. 2 Raster map of driving factors in the TMR 
population from 1996 to 2016. Gross domestic product (GDP) in TMR—which is the highest GDP in the country - was investigated from 2000 to 2015. During this period, annual GDP in the TMR grew by 17.1 (Statistical Centre of Iran, 2015), which was considered in the model. The average annual precipitation in the region was $320 \mathrm{~mm}$ per year, and the average temperature was $16.4{ }^{\circ} \mathrm{C}$. In this study, data from the Iran Environment Department and the International Report on Climate Change in Iran were used. In this report, Iran's climate changes were divided into ten regions by 2100, according to the UNDP and UNFCCC scenarios (Iran department of environment 2015) (Table 1).

\subsection{Analytical method}

In this study, future land-use change scenarios in TMR by 2030 are simulated by combining spatial and quantitative factors. The model consists of three parts of the LR, SD, and CA. In the influence of spatial factors on land-use changes, LR is entered and based on socioeconomic and climate factors SD model is combined at the quantitative demand for each land use to the scenarios. CA processes spatial allocation of land use over time and based on demand for each use, emphasizing transition potentials and neighborhoods. The overall process of these methods in conjunction with each other is depicted in (Fig. 3).

\subsubsection{Transition potential and logistic regression}

LR model output is used to provide potential transmission maps. In the modeling process, the influence coefficient of each factor needs to be measured. LR is an empirical estimation model that evaluates the relationship between a set of independent variables and a classified dependent variable, showing the transition potential map on the horizon (Puertas et al. 2014). One of the features of this model is its ability to use many independent variables in its implementation. The dependent variable in this model has a binary nature ( 0 and 1$)$; independent variables can be continuous or binary. The basic assumption in this method is that the dependent variable gains value 1 (Mahmoodzadeh and Khoshroy 2015). The value 1 indicates the occurrence of an event, and the value 0 indicates the non-occurrence of the event. Therefore, Eq. (1) derived from LR is as follows (P. Sun et al. 2016):

$$
\log \left(\frac{P_{i}}{1-P_{i}}\right)=\beta_{0}+\beta_{1} X_{1 i}+\beta_{2} X_{2 i}+\ldots+\beta_{n} X_{n i}
$$

Here, $\mathrm{P}_{\mathrm{i}}$ is the probability of occurrence for the land-use type $\mathrm{i}$; $\mathrm{X}$ indicates the driving factors; $\mathrm{n}$ is the number of the driving factors; $\beta_{\mathrm{n}}$ is the regression coefficient; and $\beta$ is the

Table 1 Spatial and quantitative data in the modeling process

\begin{tabular}{lll}
\hline Spatial Data & & Quantitative Data \\
\hline Land use in 1985, 2000 and 2015 & $\begin{array}{l}\text { Distance to population centers } \\
\text { Distance to a surface water body }\end{array}$ & $\begin{array}{l}\text { Gross domestic product (GDP) } \\
\text { Dlope }\end{array}$ \\
$\begin{array}{l}\text { Deight } \\
\text { Distance to main roads }\end{array}$ & Average annual precipitation \\
$\begin{array}{l}\text { Distance to agricultural lands } \\
\text { Distance to grasslands }\end{array}$ & Distance to railway & Average temperature \\
\hline
\end{tabular}




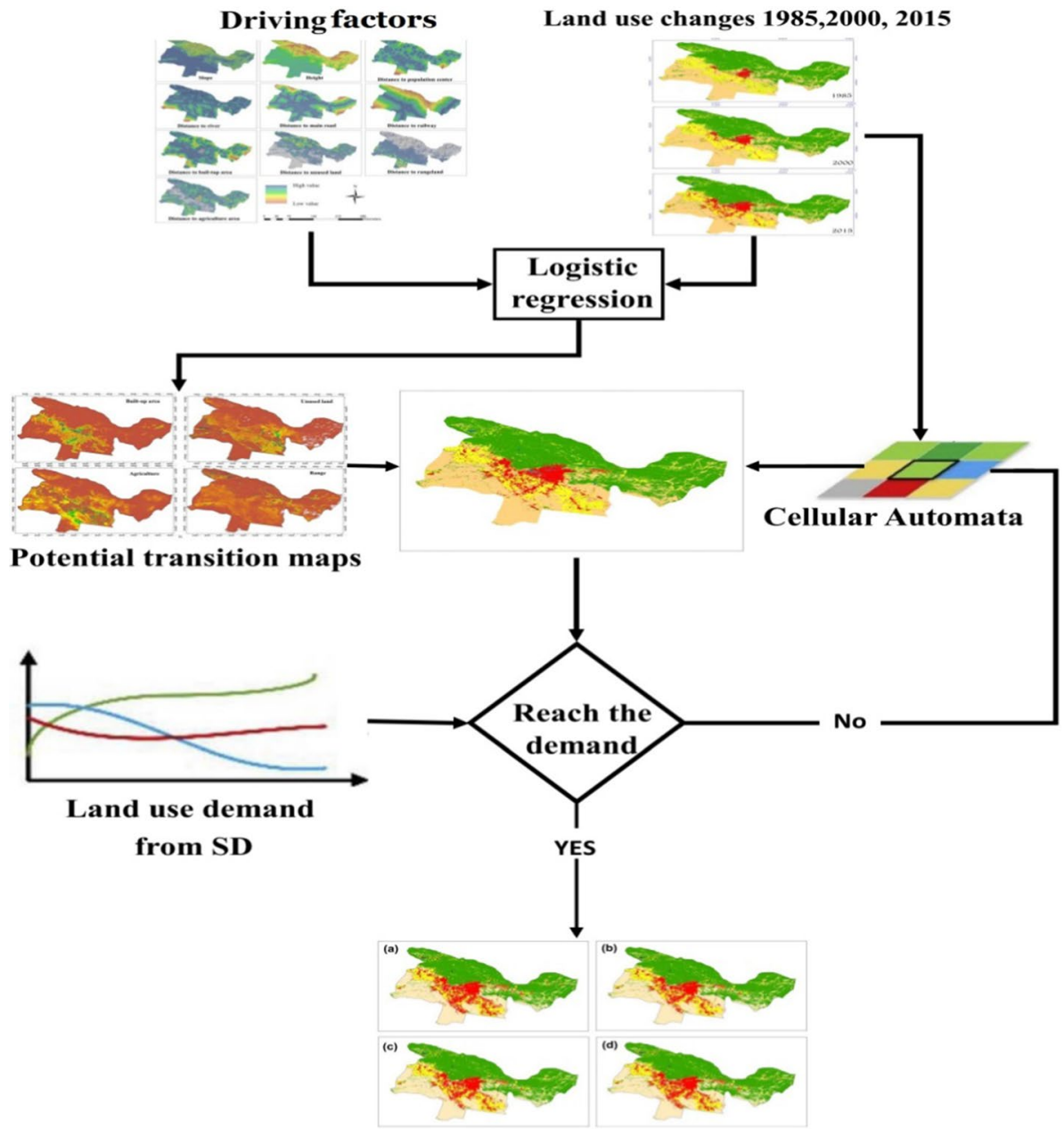

Land use scenarios in 2030

Fig. 3 The general structure of the simulation of future land-use change scenarios

constant coefficient. The LR model's output will be the transition potential map of land uses and the coefficient of the effect of each factor on the land-use change. The transition potential map spatially shows the transition probability of land use through modeling. The transition potential map is a map with grid values between 0 and 1 . The higher the grid value indicates a higher tendency to change. LR at the training stage determines the effective coefficient of each independent variable by using the transition map of each land use from 1985 to 2000 . Then, the transition potential map of each land use is generated based on these coefficients, factors map, and implementation of LR.

\subsubsection{Land-use demand and SD model}

In this study, land-use demand has been explained in different future scenarios using the SD model. Scenarios illustrate how the future is shaped. Identifying trends describes the 
future trend of the issue and provides the necessary strategies for change. The most appropriate strategy is selected by examining the effects of different model interventions (X. Liu et al. 2017). This model can be used to identify and predict the evolution of a complex system through feedback and interaction among different factors (Costanza and Ruth 1998; Haghani et al. 2003). Currently, the SD model is widely used in analyses and policy-making. This study has developed an SD model for different land-use demands in various scenarios according to socioeconomic factors and natural factors. Interaction and feedback of the SD model are illustrated in Fig. 4. In the generated SD model, four major issues are considered: population, economy, climate, and land use. The population is regarded as the most important factor affecting the increase in built-up areas (D. Liu et al. 2018). It, also, influences production and agricultural land, through the increase in demand for food provision. GDP is the most important indicator of economic growth accompanied by increased investments. Investments in various service and industrial sectors directly impact built-up areas and agricultural land (P. Sun et al. 2016). The two environmental factors of precipitation and temperature, which are subject to climate change, have a long-term effect on economic and social factors (Henareh Khalyani et al. 2013). These factors affect the grasslands, agricultural, and water bodies and increase/decrease these resources. Similarly, a proper increase in precipitation and temperature is effective on plants and leads to changes in cultivation and influence the amount of the product (Fig. 4).

Therefore, the relationships mentioned above and previous studies in identifying the land-use demand with SD (Geng et al. 2017), the interactive model, were obtained according to Fig. 4. Also, to validate the model and the relationships between factors, first, the value of each of the factors and the change of land use was entered into the model in the years 1985 and 2000, and the relationship between them was determined. Then, based on the data model, by 2015, the demand for each use was obtained. The result is the model validation with the correspondence of the modeling results with the reality of the land use. To assess the degree of error, the threshold value was defined. If the error is less than the threshold, the model is effective, and the result is reliable. However, if large distortions

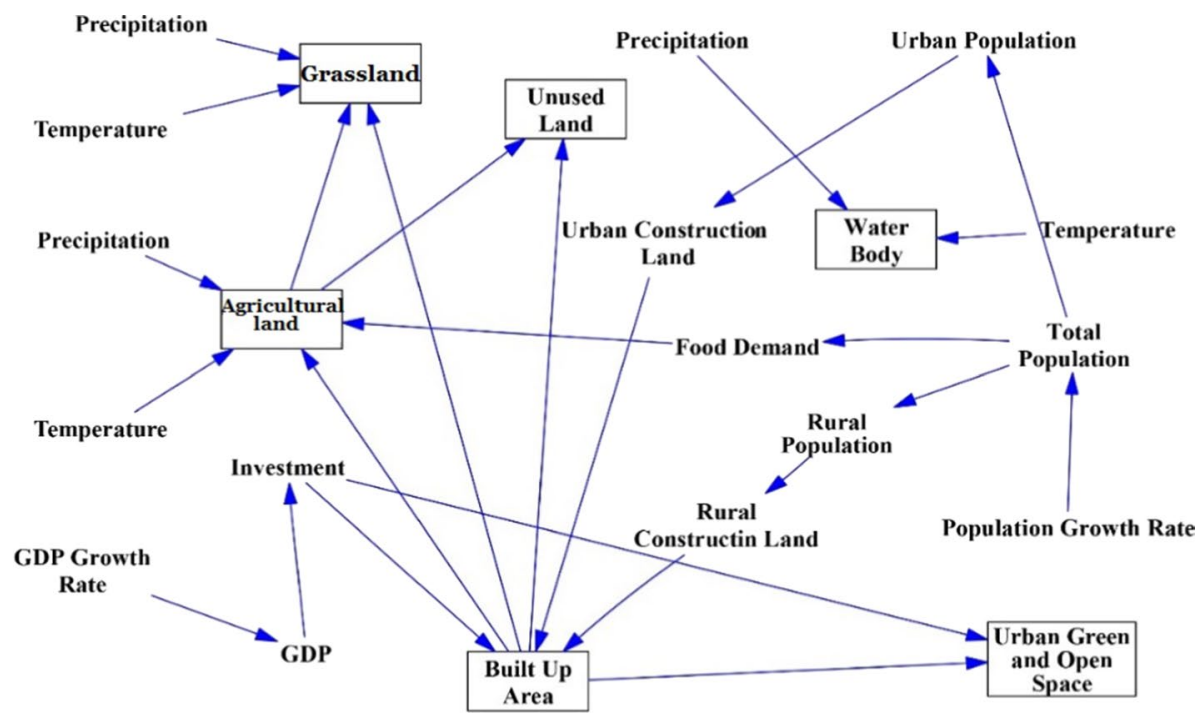

Fig. 4 The interaction of land-use types driven by socioeconomic and climate changes in the SD 
occur between similar and actual values, more modifications are required (Y. Wu, Zhang and Shen, 2011).

\subsubsection{Simulation of land-use change using CA}

The regions adjacent to the existing land use have a greater tendency to change in land use. These events can be simulated effectively using CA models. According to predefined transition rules, cellular networks in the CA model independently determine their states and adjacent neighbors. Different methods of defining the transition potentials operate differently in the CA model and generate different outputs (Cheng and Masser, 2004; Shafizadeh-Moghadam et al. 2017a, b). In the CA model, space is separated as the ordered cells, and the state of each specific cell is determined according to the state of the cell itself and its neighboring cells over the past time, through a set of transition rules that are transition potential maps (Arsanjani et al. 2012). It is also important that the spatial filters' size is determined; this size is effective in the CA process and the neighboring effect. The Von Neumann setting with four neighbors and the Moore neighborhood setting with eight neighbors are the most well-known neighborhood settings. Various filter sizes have been incorporated in CA and tested in the land change science literature. CA's most common filter sizes in the literature are $3 \times 3,5 \times 5$, or $7 \times 7$ (Liao et al. 2016). Previous studies have shown that the difference between these filter sizes was marginal in LUC simulations. A $5 \times 5$ filter had the best accuracy among other neighborhood sizes (Shafizadeh-Moghadam et al. 2017a, b). So we used this filter size as well.

The Integrated CA model with other models is an available method to overcome the CA model's limitation (Aburas, Ho, Ramli, \& Ash'aari, 2016). The integration model is strongly valid for simulating spatial and temporal processes. In recent studies, many integrated models have been developed, e.g., CA-MC, CA-LR, CLUE-s, and SLEUTH in Berberoğlu et al. (2016) study. In this study, by applying the LR model, the transition potential of each land use is entered as a part of the CA model. The combination of the CA and LR models in many studies has been used, and the accuracy and validity of the model are examined (Arsanjani et al. 2012; Goodarzi et al. 2017). Hence based on Eq. (2), the CA model was run (Y. Liu and Feng 2012):

$$
Y=P_{i}^{t}=P_{d i}^{t} \times P_{N i}^{t} \times C
$$

where $P_{i}^{t}$ represents the probability of conversion of the cell i in time t, $P_{d i}^{t}$ is the transition potential of land use based on LR maps, $P_{N i}^{t}$ is conversion probability due to neighborhood rules, and $\mathrm{C}$ is a set of constraints in land-use changes.

\subsubsection{SD and CA_LR models}

In the land-use modeling process, spatial issues are simulated by combining LR and CA, but for quantifying the demand of each land use in the scenarios, the SD model is applied (Liu et al. 2018). Over time, land-use demand is used from the SD model as an input of the CA-LR model for simulating land-use patterns. This cross-input-output feedback continues to meet demand in each scenario and ultimately simulates the land-use pattern at the end of the selected period. The demand in each scenario is determined based on the different inputs and outputs of the SD. Accordingly, by combining with CA, scenario simulation maps result (X. Liu et al. 2017). 
Here, four scenarios are defined based on these variables. As shown in Fig. 5, these scenarios are organized based on two axes: the vertical axis indicates the socioeconomic effects and the horizontal axis represents the climate changes (Fig. 5). In the CT-scenario, the changes have been made in the metropolitan region based on the previous trend. In this scenario, the economic growth rate (GDP), has increased with the past trend. Similarly, in population growth rate, the current trend is ongoing. Two variables of climate change also maintain the current annual average.

The increase in population and the development process has many consequences, including the expansion of cities and villages, the growing demand for food, agricultural and industrial development, unprincipled and unreasonable exploitation regardless of land capability and ecological carrying capacity (Walsh et al. 2006). In recent years, environmental degradation has accelerated and has caused irreparable damage to natural resources. In the EO-scenario, to protect nature and natural resources and control the lower growth rates of built-up areas, the average values of the climate variables are higher, and the population and GDP growth rates are lower than in the past. As the country's political and administrative capital, Tehran has the largest activity and employment opportunities; it is also considered the center of services in the country (Alidadi and Dadashpoor 2018). Accordingly, in the SEG-scenario, the axis of the socioeconomy has the greatest impact. The economy and population have the highest pace of growth. In the ID-scenario, the emphasis is on the integrated development of all factors and sustainable development goals. In this way, the result will be socioeconomic development and the improvement of the climate factors.

\subsubsection{Validation}

Validation of LR and CA models with Relative Operating Characteristic (ROC) and Kappa coefficient has widely been used to highlight the validity of simulation (Azari et al. 2016; $\mathrm{Ku}$ 2016). These criteria represent the correspondence between reality and the simulated model. In LR, the ROC criterion is a value between 0 and 1 . Value 1 represents a complete spatial agreement. The value of 0.5 represents the spatial randomness of the uses, showing that the transition potential was created in this method as random spaces. In the studied

\begin{tabular}{|c|c|}
\hline Current trend scenario & \\
\hline Unchanged population growth rate & Increase population growth rate \\
\hline Unchanged GDP growth rate & Increase GDP growth rate \\
\hline Decrease Annual Precipitation & Decrease annual precipitation \\
\hline Increase annual temperature & Increase annual temperature \\
\hline Integrated development scenario & Ecological Oriented scenario \\
\hline Moderate population growth rate & Decrease population growth rate \\
\hline Moderate GDP growth rate & Decrease GDP growth rate \\
\hline Moderate Annual Precipitation & Moderate annual precipitation \\
\hline Moderate Annual Temperature & Moderate annual temperature \\
\hline
\end{tabular}

Fig. 5 Structure of the four scenarios by the driving factors of socioeconomic and climate changes in the SD model 
region, the simulated and real maps for 2015 were adopted. The benefits of the Kappa coefficient are to use all the values of the comparison matrix to calculate the accuracy. The following relationships show how to obtain the overall accuracy and kappa coefficient from the comparison matrix:

$$
\text { Kappa }=\frac{\sum_{i=1}^{c} P_{i i}-\sum_{i=1}^{c} P_{i T} \cdot P_{T i}}{1-\sum_{i=1}^{c} P_{i T} \cdot P_{T i}}
$$

Here, $\mathrm{i}=1, \ldots, \mathrm{c}$ represents the existing uses in the region; $\mathrm{P}_{\mathrm{ii}}$ represents the pixels of the use $\mathrm{i}$ in the reality and simulated model; $\mathrm{P}_{\mathrm{ij}}$ represents the pixels of the use $\mathrm{i}$ in the reality that is in the use $\mathrm{j}$ in the simulation; $\mathrm{P}_{\mathrm{iT}}$ represents the total number of pixels of class $\mathrm{i}$ in reality, and $\mathrm{P}_{\mathrm{Ti}}$ represents the total number of pixels of class $\mathrm{i}$ in the simulated model. Overall accuracy varies between 0 and 1 . The value closer to 1 indicates that the model is more in line with reality. Kappa coefficient of less than 0.4 shows that the model is weak, and the Kappa coefficient higher than 0.8 represents the model's power in the simulation.

\section{Results}

\subsection{Land-use change detection}

The land-use change in the case study between 1985 and 2015 shows that these changes have increased significantly (Fig. 6). While the area of agricultural land, grassland, and unused land as valuable natural resources decreased, the area of built-up land had an increasing trend during the studied period. The area of the built-up land in 1985 was 353 $\mathrm{km} 2$, which reached $1327 \mathrm{~km} 2$ in 2015 . The share of built-up areas has risen from 2.1 percent to 7.88 percent, indicating major urban expansions over the period. The area of
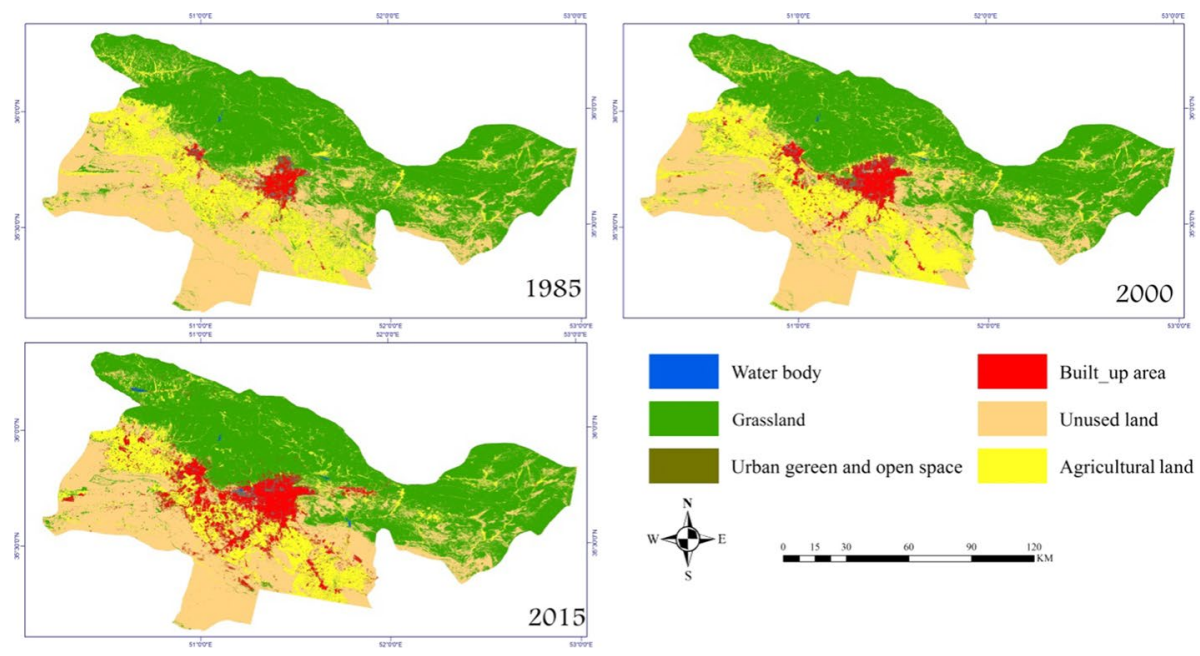

Fig. 6 Land-use changes in the TMR between 1985, 2000 and 2015 
grasslands decreased by 2 percent. This kind of land covered 47.44 percent $\left(7997 \mathrm{~km}^{2}\right)$ of the total area in 1985 , which reduced to 45.43 percent $\left(7657 \mathrm{~km}^{2}\right)$ of the total area of the TMR in 2015. The share of agricultural land of the total land decreased from 16 to $14 \%$ and the unused areas decreased from 34 to $31 \%$ from 1985 to 2015.

Spatial changes in the built-up areas show that most of these changes have occurred around urban areas, especially in Tehran and Karaj's peripheral areas. Land-use changes between 1985 and 2000 show that most of these changes have occurred in Tehran's Southern green corridor, mainly agricultural lands, leading to the destruction of these lands, especially between Tehran and Karaj. In the years 2000 to 2015, the trend of change has been transferred to the east and the southeast of Tehran and has intensified the destruction of natural lands in these areas (Table 2).

\subsection{Driving factors of land-use changes}

The influence coefficient of each of these variables was determined using LR (Table 3). In agricultural land change, the driving factors including height, distance from population centers, distance from the built-up areas, and land slope are the most influential factors, respectively. Regarding unused land, distance from unused lands, height, and distance from built-up lands have the highest influence. There is a direct relationship between reduced agricultural and unused lands and proximity to built-up areas. Because the built-up areas are generally spread around the metropolises and cities due to the continuous growth. Therefore, the closer the land uses are to the built-up areas, the more likely they are to change. Meanwhile, the slope is a limiting factor for developing the built-up areas with a coefficient of -5.12 , which is effective in changing these areas. The position of the main roads is the third factor that influences change. Areas closer to the road network have more potential to change in the built-up areas. In the grassland change of the region, the distance from the existing grasslands and the main rivers running in the northern parts of the region and the built-up areas that have destroyed the grassland, have had the greatest impact on the change.

\subsubsection{Transition potential maps}

In the land-use transition potential maps (Fig. 7), the unused areas indicate the greatest transition potential. The east and southeast areas have the greatest potential for change.

Table 2 Area and percentage of land-use changes in 1985, 2000, and 2015

\begin{tabular}{|c|c|c|c|c|c|c|}
\hline \multirow[t]{2}{*}{ Land use } & \multicolumn{2}{|l|}{1985} & \multicolumn{2}{|l|}{2000} & \multicolumn{2}{|l|}{2015} \\
\hline & Area $\left(\mathrm{km}^{2}\right)$ & Percent & $\operatorname{Area}\left(\mathrm{km}^{2}\right)$ & Percent & $\operatorname{Area}\left(\mathrm{km}^{2}\right)$ & Percent \\
\hline Built-up area & 353.32 & 2.1 & 644.94 & 3.83 & 1327.6 & 7.88 \\
\hline Agricultural land & 2744.47 & 16.28 & 3113.45 & 18.47 & 2497.45 & 14.82 \\
\hline Urban green and open space & 48.16 & 0.29 & 82.16 & 0.49 & 91.64 & 0.54 \\
\hline Grasslands & 7997.06 & 47.44 & 7673.73 & 45.52 & 7657.4 & 45.43 \\
\hline Unused land & 5707.5 & 33.86 & 5337.77 & 31.67 & 31.23 & 31.23 \\
\hline Waterbody & 6.18 & 0.04 & 4.64 & 0.03 & 0.1 & 0.1 \\
\hline Sum area & $16,856.73$ & 100 & $16,856.73$ & 100 & 100 & 100 \\
\hline
\end{tabular}


Table 3 The influence coefficient of driving factors on land-use changes

\begin{tabular}{lrrrr}
\hline Driving factors/land use & Grassland & Built-up area & Unused land & Agricultural land \\
\hline Distance to agricultural lands & 0.2729 & 1.1681 & 0.7834 & 0.9549 \\
Distance to unused lands & -0.1284 & 0.0125 & 6.5813 & -1.9788 \\
Distance to the built-up area & 2.7512 & 13.6859 & 2.5099 & 2.8546 \\
Distance to population centers & 0.8462 & 1.0527 & -1.5736 & 5.0628 \\
Distance to the main road & -0.3856 & 3.1001 & 0.3851 & -0.6458 \\
Distance to railway & -0.8098 & 0.7554 & -2.7983 & -0.0209 \\
Distance to grassland & 6.6276 & 0.9115 & -0.4722 & -3.1559 \\
Distance to river & 2.2944 & 0.3771 & -0.2105 & -0.9295 \\
Height & -2.3598 & -2.8938 & 3.8101 & 8.8603 \\
Slope & -3.1232 & -5.1202 & 0.5504 & 1.6886 \\
Intercept & -8.8726 & -14.7295 & -7.454 & -3.532 \\
\hline
\end{tabular}

In the west of the TMR, the main axis of the Tehran-Karaj, Eslamshahr axis, and the western part of Karaj have the most potential to transform from unused into other types of land use. In the future, these areas could be used as potential areas for the expansion of the built-up areas due to the appropriate slope, proximity to the road, and built-up areas. In the use of grassland, the northern parts of these areas have the greatest transition potential. By the way, the southern parts of the region have the least potential for grassland conversion. These areas are mostly arid, semiarid, and desert, and cannot expand vegetation, as can be seen in the transition potential maps.

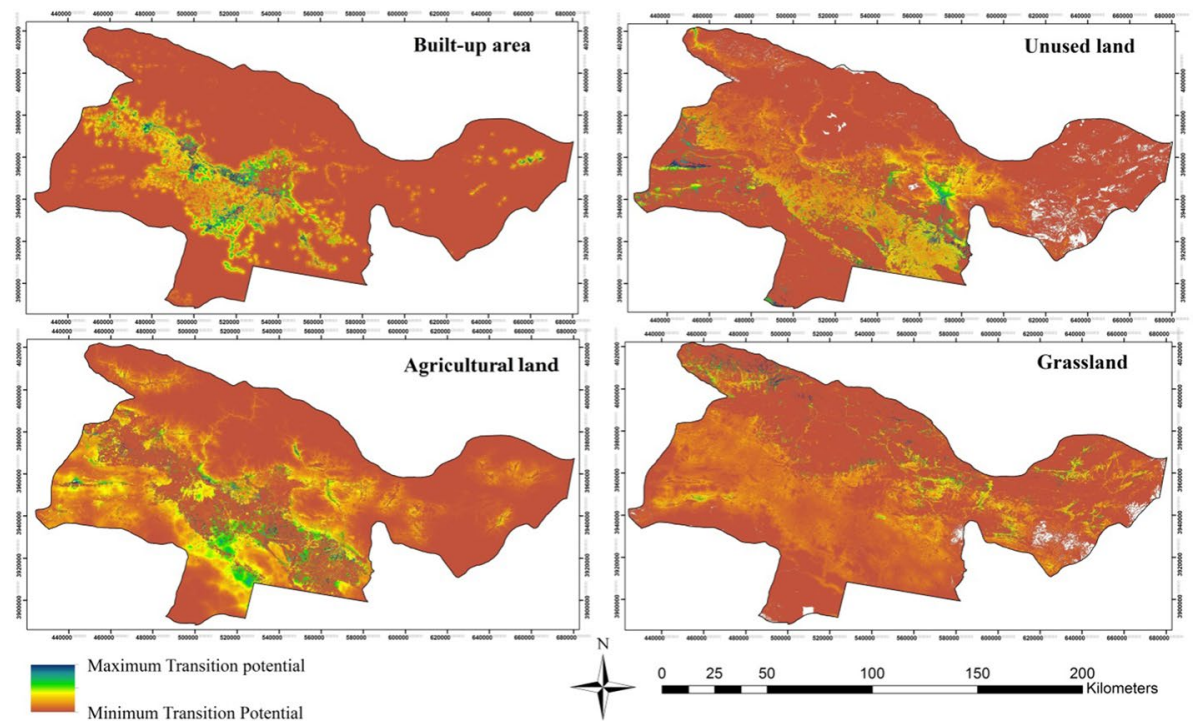

Fig. 7 Potential transition map of land-use changes in the TMR 
Table 4 ROC coefficient in transition potential maps in the LR model

\begin{tabular}{lllll}
\hline Land use & Agricultural & Unused & Built-up & Grassland \\
\hline ROC & 0.9248 & 0.9563 & 0.9628 & 0.9352 \\
\hline
\end{tabular}

Table 5 Socioeconomic and climate changes in scenario simulation

\begin{tabular}{lllll}
\hline Scenario & $\begin{array}{l}\text { GDP } \\
\text { rate(percent) }\end{array}$ & $\begin{array}{l}\text { Population } \\
\text { grow rate }\end{array}$ & $\begin{array}{l}\text { Average annual pre- } \\
\text { cipitation change }\end{array}$ & $\begin{array}{l}\text { Average } \\
\text { annual tem- } \\
\text { perature }\end{array}$ \\
\hline Current trend & 17.1 & 2.2 & 0 & 16.4 \\
Ecological-oriented & 15 & 2 & 1.5 & 16.3 \\
Socioeconomic growth & 19 & 2.4 & -1.2 & 16.5 \\
Integrated development & 18 & 2.3 & 1 & 16.3 \\
\hline
\end{tabular}

\subsection{Validation of $L R$ and $C A$}

The output of LR is the potential transition maps, in which the minimum to maximum transition potential is specified in each land use. Thus, the places with the most transition in the future are more likely to change land use. Validation of LR maps was performed by the ROC method (Table 4). The ROCs greater than 0.8 for all land-use types show high accuracy of the method to explain land-use changes. The highest accuracy is observed in built-up lands.

According to the coefficients of ROC in (Table 4), the accuracy of agricultural lands modeling is less than the other three uses, which is justified by the fact that this use is changing over the year; and also another reason may relate to the low accuracy of the classification of this use. Built-up use has higher accuracy than other uses, which can be because the new areas are created by certain rules, but in other uses, there are no specific rules for creating changes (Dadashpoor \& Salarian 2020). Accordingly, the land-use map in 2015 was modeled. To validate the model, the classified land-use map was compared to the modeled land-use map. Kappa coefficient in this comparison was 0.845 . This percentage indicates a high degree of modeling accuracy, which now can be modeled for the year 2030 based on this method.

\subsection{Scenarios and quantitative changes}

Using the SD model, the influence of each driving factor (population, GDP, precipitation, and temperature) on the land-use demand was determined in each scenario from 2015 to 2030. As mentioned, four parameters are introduced to the SD model. Each of these factors and the extent of its changes in land-use scenarios for the TMR in 2030 are listed in Table 5. In the CT-scenario, the annual population growth rate of 2.2 continues as in the past. GDP growth of 17.1, as well as the climate changes (precipitation and temperature), remains unchanged. In the ecologically oriented scenario, socioeconomic dimensions and climate changes take a different trend. The population growth rate in the metropolitan region is assumed to be 2 per annum. The GDP growth rate is $15 \%$ and the average annual precipitation increases by $1.5 \%$ over the entire 15 -year period. The temperature drops by 
0.1 degrees Celsius. In the SEG-scenario, population and GDP growth rates increase by 2.4 and 19 percent, respectively. The average variations in precipitation decreases by -1.2 percent and the temperature rises $0.1{ }^{\circ} \mathrm{C}$ from the average annual. In the ID-scenario, all factors and their changes are considered interactively and homogeneously.

\subsubsection{Land-use demand in scenarios}

The SD model is performed in each scenario for land-use demand. Land-use demand in each scenario is illustrated in Fig 8. The built-up areas in all four scenarios will take an increasing trend to different degrees until 2030. In the trend scenario, the built-up area increased by $2709 \mathrm{~km}^{2}$, and the grassland and agricultural lands decreased by $7356 \mathrm{~km}^{2}$ and $2231 \mathrm{~km}^{2}$, respectively. In the SEG-scenario, on the one hand, the built-up area rapidly grows, covering the area of $2858 \mathrm{~km}^{2}$. The rapid growth of this land use is due to the rapid urban population and economic growth that requires an increase in urban areas to accommodate this population. On the other hand, agricultural land and grassland
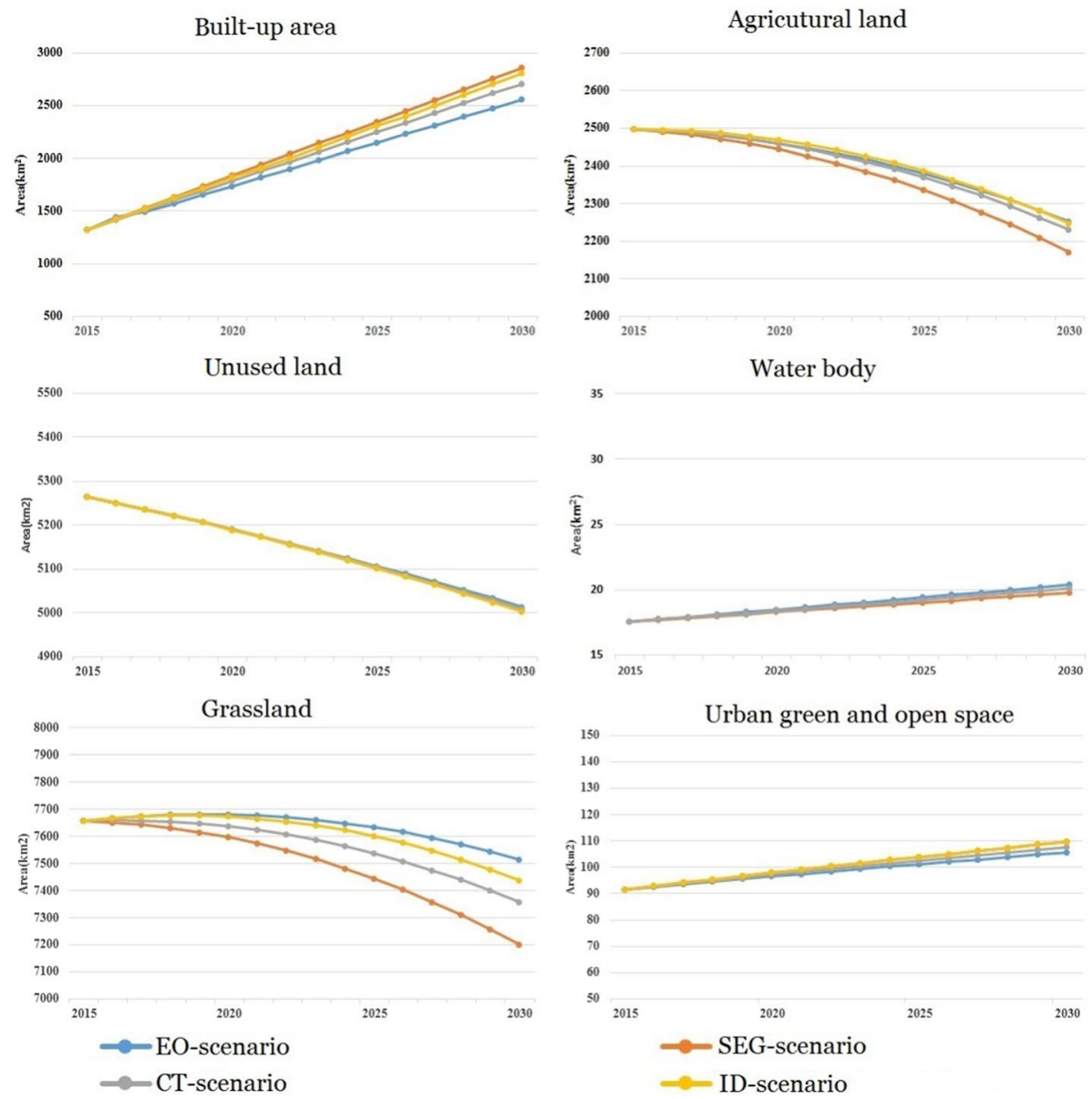

Fig. 8 Land-use demands under different scenarios from 2015 to 2030 
decrease by $2171 \mathrm{~km}^{2}$ and $7201 \mathrm{~km}^{2}$. On the contrary, the lowest growth of built-up areas is seen in the EO-scenario by $2560 \mathrm{~km}^{2}$. In the ID-scenario, the built-up area will reach $2808 \mathrm{~km}^{2}$ in 2030 . The grassland area will moderately decrease to $7438 \mathrm{~km}^{2}$ in this scenario, but the amount of decrease is relatively less than SEG and CT-scenario.

\subsection{Spatial simulation of scenarios}

According to the defined scenarios, each land use will have a specific area in 2030. Each spatial scenario has been spatially developed based on the potential transmission maps in the LR model and neighborhood rules in the CA model. In comparison with 2015, changes in the built-up areas in the scenarios occur around Tehran and Karaj.

In the CT-scenario, changes are mainly witnessed in the built-up areas. TMR has had a wide urbanization process in the past, and this trend can be imagined in the future. The changes from 1985 to 2015 show rapid growth in urban and rural areas and a decrease in green land use. Accordingly, the changes in built-up lands by 2030 will also increase and go through as in the past. Spatial changes in this use will take place in the west of Tehran and the Tehran-Karaj axis. Tehran-Varamin axis in the southeast and Eslamshahr-Shahryar axis in the southwest show the most changes. In this challenge, the conversion of other land uses into built-up land is more visible, and areas in the proximity of urban and rural areas are destroyed and converted into residential, industrial, and service areas. Most of the agricultural areas are located in the south of Tehran, which has a severe decreasing trend in this scenario so that a large part of agricultural resources in the south of Tehran will be destroyed. The region's grasslands are mostly extended in the north and east of the region where most reduction of this type of land use occurs in the new town of Pardis and the north of Tehran.

In the EO-scenario, although urban areas will generally grow, the main growth will occur near the main cities, specifically in the Tehran-Karaj axis. In this scenario, urban areas' growth rate will be the lowest compared to other scenarios, and urban dispersion in the east and west of the region will occur with less intensity. Also, agricultural lands in the southwest will remain stable, and grassland will not decrease except for the region's eastern part. This may be due to sufficient rainfall and the right temperature in this scenario.

In the SEG-scenario, which shows the socioeconomic growth in the TMR, the builtup areas will have significant growth along the main roads. Edge growth pattern will occur near industrial areas in the west and southeast, as well as adjacent to the exiting manufactured areas. In the eastern part of the region, spots made from areas that are signs of leapfrog growth will also be observed. The agricultural and unused lands located in the south and west will be threatened by the growth of the built-up areas and will convert into new built-up areas. In this scenario, the largest destruction of natural resources will take place. Agricultural lands rapidly will convert into built-up areas; Climate change will have a reverse trend in this scenario.

The ID-Scenario is more human-centered and pursues sustainable development goals. The grassland pattern of this scenario will be similar to the EO-scenario, even though the influence of socioeconomic factors on this scenario is different. Also, water bodies, including dams and artificial lakes, will remain unchanged. The built-up areas will increase slightly, and more urban growth will occur in the south of the region where unused land is adjacent to major cities and main roads (Fig. 9). 


\section{Discussion}

This study attempted to simulate the future scenario of land-use changes based on socioeconomic and climate change factors in the TMR between 1985 and 2030. At first, landuse changes and their driving factors were analyzed. In the past three decades, the TMR has faced with urban sprawl and unmanageable growth of the built-up areas. The spatial structure of land-use changes were characterized by the decline in grassland, agricultural land, unused land, and the increase in built-up areas and urban open spaces. The spatial pattern of land use indicates that most changes have occurred in the west and south of Tehran metropolis where the industrial areas and suburban areas are located. Urban sprawl tends to occur close to the industrial areas and main roads. Also, the expansion of the builtup areas has damaged the natural open lands and degraded the region's ecological areas. In the spatial analysis, as shown in the studies carried out on the TMR ( Alaei Moghadam and Karimi 2016; Arsanjani et al. 2012), the built-up areas, first, expanded around the Tehran and Karaj and, then, in southwest and west of Tehran metropolis in the form of a linear and leapfrog expansion. This result reveals that land-use changes in the metropolitan regions are mostly rooted in expanding urban areas (Dadashpoor 2019a). Under the current circumstances, the land-use change will lead to unsustainable development, making scenario building necessary for exploring and managing these changes.

In this study, driving factors have been analyzed using the LR model, which has high accuracy and validity in analyzing these factors (Arsanjani et al. 2012; Luo and Wei 2009). As results indicate, proximity to roads and population centers significantly impact urban growth and built-up areas, leading to a decrease in unused and agricultural lands in the region. In TMR, the high transition potential of western areas, specifically the TehranKaraj axis, demonstrates this issue. These results comply with other studies who believe that accessibility to the main roads and proximity to cities play a significant role in
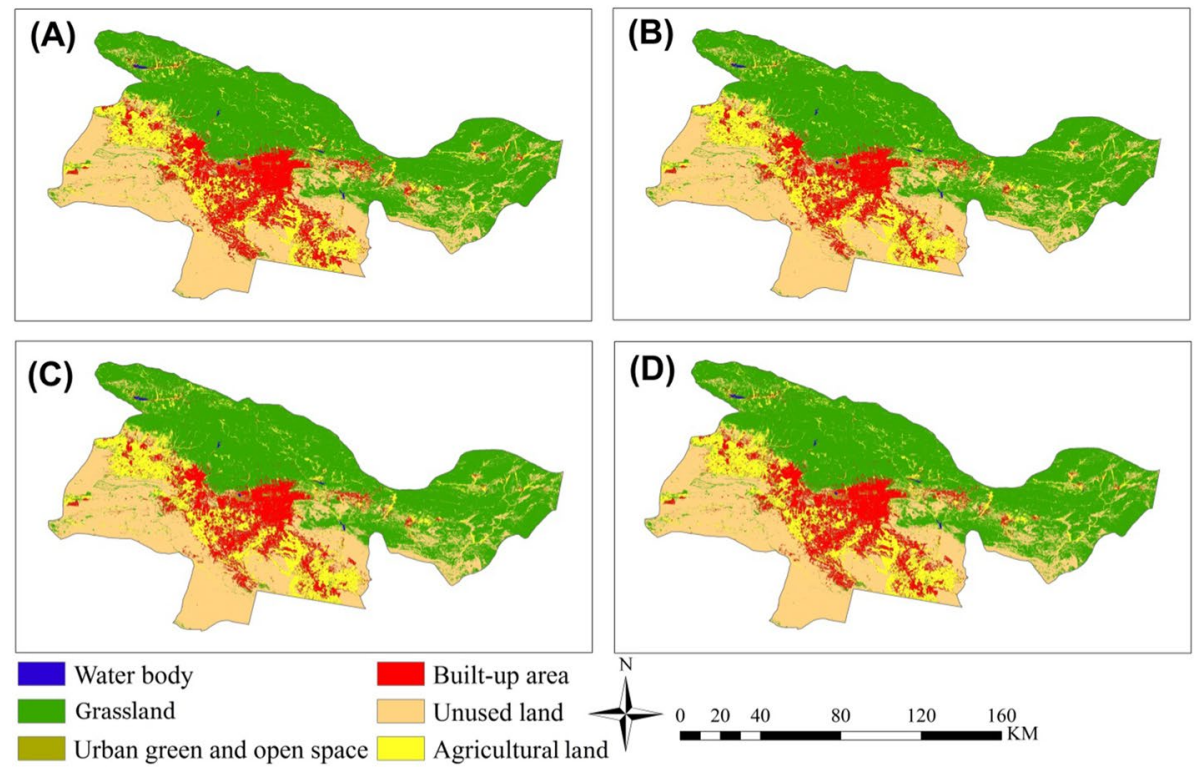

Fig. 9 Scenario simulation maps in 2030, a: CT-scenario, b: EO-scenario, c: ID-scenario, d: SEG-scenario 
land-use changes where new built-up areas tend to grow continuously along with existing cities (Dadashpoor and Azizi 2019b; Dadashpoor and Nateghi 2017; Maimaitijiang et al. 2015; Shafizadeh-Moghadam et al. 2017a, b; Xiaojun Yang and Lo 2003). Moreover, proximity to population centers and built-up areas have significant impacts on agricultural land change. The destruction of agricultural lands in metropolitan areas mainly occurs due to the expansion of built-up areas (Moein et al. 2018). Also, height and slope have always been influential in the development of agricultural lands. In the south and west of the region where there are appropriate soil, water, and slope, agricultural lands have developed further. The results in this section indicate that LR was effective and efficient in explaining the influence of driving factors.

Accordingly, four scenarios were modeled by focusing on socioeconomic factors (population and GDP) and climate change factors (precipitation and temperature). The spatial simulated scenarios include the CT-scenario, SEG-scenario, EO-scenario, and ID-scenario. The analysis of the spatial pattern of these scenarios indicates that in comparison with the land-use pattern in 2015, the expansion of built-up areas in will occur all four scenarios until 2030. This expansion will primarily locate in proximity to existing built-up areas, especially in SEG-scenario and CT-scenario. In TMR, agricultural and grassland lands (as the valuable natural lands) will be destroyed with an increase in built-up lands. This trend occurs at different rates in Quadruple scenarios. In the EO-scenario, agricultural and grassland lands will have the lowest reduction. In the SEG-scenario, the decline will be more destructive. The change of unused land will remain steady in all scenarios. Thus, urban changes will affect other land uses in the TMR. Scenarios simulation indicates that while the CT-scenario can lead to high growth in the built-up areas with destructive impacts on natural and green open spaces, the ID-scenario will positively impact agricultural and grassland and economic and social betterment. The ID-scenario focuses on the sustainability of natural resources in parallel with addressing economic growth and social equity. This scenario can be explained in various ways; economic sustainability seeks more efficient allocation and management of resources and social sustainability. It improves social equity and fair distribution of the population and services in the TMR. Previous scenario-based studies conducted in the metropolitan areas in China (Han et al. 2015; X. Liu et al. 2017), Iran (Bihamta et al. 2015; Dadashpoor and Azizi 2019a), Latin America (Puertas et al. 2014) and Europe (Mancosu et al. 2015; Silva and Clarke 2005) demonstrate that the urban expansion has occurred around existing built-up areas and close to the main roads, causing destructive impacts on natural areas. Therefore, policy-makers must consider driving factors of future scenarios and the consequences of different scenarios.

This study indicates that the simulation of land-use changes in metropolitan regions based on just one specific model is difficult since these regions have high complexity. Therefore, the combination of models is necessary to simulate future scenarios. In this study, the CA model was combined with SD and LR models to develop a comprehensive and efficient model for the simulation of land-use changes in the TMR, focusing on socioeconomic and climate changes. The LR model has a high potential for explaining the relationship between land-use change and the driving factors and has an effective contribution to explain the influential variables. However, this model has also limitations in the modeling of quantitative changes and allocation of changes (Arsanjani et al. 2012). The CA model has also been recognized as an efficient model for simulation of land-use changes (Batty et al. 1999; Liu et al. 2019) which has been widely used in most studies. Due to extensive land-use changes in the TMR as well as the high complexity of socioeconomic factors influencing this region, modeling based on both socioeconomic and natural-environmental factors was responsive. Thus, in the scenario-making process for future land-use 
changes, the SD (as an efficient model) modeled land-use demands focusing on socioeconomic and climate change factors.

This article attempted to show that the combined method (LR-SD-CA) offers certain advantages over traditional methods. Initially, this combined method can consider and integrate natural (climate changes) and socioeconomic factors that are not considered in the CA-based models such as SLEUTH (Silva and Clarke, 2002). Secondly, any spatial factor can be introduced to this approach to measure its impact on land-use change such as distance from existing artificial elements, slope, and height. Finally, the approach was validated and approved in two stages: preparing the transition potential maps by ROC and comparing the actual and simulated map for 2015 which increases the reliability of landuse maps in future land-use changes. In this study, the results of ROC and Kappa coefficients indicate high validity and demonstrate that the proposed model can simulate landuse changes in a dynamic process.

\section{Conclusion}

In the present article, land-use changes of the TMR in the past decades were initially explored. The study revealed the significant growth of the built-up areas from 1985 to 2015. This growth can be attributed to the growth of economic and industrial activities in the TMR and as a consequence, its demographic attraction and, with the need of this population for housing, the built-up areas have increased. The expansion of built-up areas to provide the land needed for growth has invaded green and valuable open spaces, leading to destroy these uses in the region. Therefore, the main reason for the decrease in natural lands has been increased residential and industrial uses. In this study, the influence of spatial factors on land-use change was explained. In natural area changes; height, proximity to population centers, slope, and proximity to built-up areas have been most impacted. The distance to the main road is another influential factor in land-use change.

In this study, the LR, SD, and CA models were combined with three major purposes: First, LR is useful for building probability levels and exploring places with the highest probability of change for the development of each land use and identifying the extent to which each factor affects the change in land use. Second, the SD model was used to obtain quantitative changes in the area of each land use in different scenarios based on socioeconomic and climate changes. Third, the CA model is a powerful tool for allocating the probability changes to pre-determined rules. CA allocates the rate of changes with the highest probability. Thus, this integrated method can simulate scenarios under quantitative and spatial models. The proposed model was applied to simulate four scenarios of land-use changes in the TMR to show the applicability of the model. The scenario results demonstrate that this integrated model can be used to explain the important factors of changes and the core area of changes. It is also very effective to recognize the impacts of the socioeconomic factors on land-use changes, which can help urban and regional planners and policymakers understand current and future problems in land-use changes and choose the most appropriate strategies for managing these changes.

However, despite its strengths, this method has some limitations. Although this combined method can accommodate various driving factors, certain limitations include a lack of focus on individuals' behavior, political economy, and government measures to change the land use, which cannot be modeled with this combined method. Extensive studies carried out in different metropolitan regions worldwide can provide an integrated view of the 
main driving factors of change in these regions. Also, by studying the qualitative dimensions of land use, we can reach more probable scenarios covering all driving factors. Therefore, further studies are needed to combine quantitative and qualitative factors for understanding and managing land-use change in metropolitan areas.

\section{References}

Abuelaish, B., \& Olmedo, M. T. C. (2016). The scenario of land use and land cover change in the Gaza Strip using remote sensing and GIS models. Arabian Journal of Geosciences, 9(4), 2292-2297.

Al-shalabi, M., Billa, L., Pradhan, B., Mansor, S., \& Al-Sharif, A. A. A. (2013). Modeling urban growth evolution and land-use changes using GIS-based cellular automata and SLEUTH models: The case of Sana'a metropolitan city. Yemen. Environmental Earth Sciences, 70(1), 425-437.

Al-sharif, A. A. A., \& Pradhan, B. (2014). Monitoring and predicting land-use change in Tripoli Metropolitan City using an integrated Markov chain and cellular automata models in GIS. Arabian Journal of Geosciences, 7(10), 4291-4301.

Alaei Moghadam, S., \& Karimi, M. (2016). The modeling growth pattern of urban patches using a patchgrowing algorithm based on cellular automata in the Tehran megalopolitan area. Journal of Geospatial Information Technology, 4(3), 89-107.

Alidadi, M., \& Dadashpoor, H. (2018). Beyond monocentricity: examining the spatial distribution of employment in the Tehran metropolitan region. Iran. International Journal of Urban Sciences, 22(1), 38-58.

Arsanjani, J. J., Helbich, M., Kainz, W., \& Boloorani, A. D. (2012). Integration of logistic regression, Markov chain, and cellular automata models to simulate urban expansion. International Journal of Applied Earth Observation and Geoinformation, 21(1), 265-275.

Arsanjani, J. J., Kainz, W., \& Mousivand, A. J. (2011). Tracking dynamic land-use change using spatially explicit Markov chain based on cellular automata: The case of Tehran. International Journal of Image and Data Fusion, 2(4), 329-345.

Arunyawat, S., \& Shrestha, R. P. (2018). Simulating future land use and ecosystem services in Northern Thailand. Journal of Land Use Science, 00(00), 1-20.

Azadi, H., Barati, A. A., Rafiaani, P., Raufirad, V., Zarafshani, K., Mamoorian, M., \& Lebailly, P. (2016). Agricultural Land Conversion Drivers in Northeast Iran: Application of Structural Equation Model. Applied Spatial Analysis and Policy, 9(4), 591-609.

Azari, M., Tayyebi, A., Helbich, M., \& Reveshty, M. A. (2016). Integrating cellular automata, artificial neural network, and fuzzy set theory to simulate threatened orchards: Application to Maragheh. Iran. GIScience and Remote Sensing, 53(2), 183-205.

Batty, M., Xie, Y., \& Sun, Z. (1999). Modeling urban dynamics through GIS-based cellular automata. Computers, Environment and Urban Systems, 23(3), 205-233.

Berberoğlu, S., Akin, A., \& Clarke, K. C. (2016). Cellular automata modeling approaches to forecast urban growth for Adana, Turkey: A comparative approach. Landscape and Urban Planning, 153, 11-27.

Bihamta, N., Soffianian, A., Fakheran, S., \& Gholamalifard, M. (2015). Using the SLEUTH Urban Growth Model to Simulate Future Urban Expansion of the Isfahan Metropolitan Area. Iran. Journal of the Indian Society of Remote Sensing, 43(2), 407-414.

Cheng, J., \& Masser, I. (2004). Understanding spatial and temporal processes of urban growth: Cellular automata modeling. Environment and Planning B: Planning and Design, 31(2), 167-194.

Costanza, R., \& Ruth, M. (1998). Using dynamic modeling to scope environmental problems and building consensus. Environmental Management, 22(2), 185-195.

Dadashpoor, H., Azizi, P., \& Moghadasi, M. (2019a). Analyzing spatial patterns, driving forces, and predicting future growth scenarios for supporting sustainable urban growth : Evidence from Tabriz metropolitan area. Iran. Sustainable Cities and Society, 47, 101502.

Dadashpoor, H., Azizi, P., \& Moghadasi, M. (2019b). Land-use change, urbanization, and change in landscape pattern in a metropolitan area. Science of the Total Environment, 655, 707-719.

Dadashpoor, H., \& Ahani, S. (2021). Explaining objective forces, driving forces, and causal mechanisms affecting the formation and expansion of the peri-urban areas: A critical realism approach. Land Use Policy, 102, 105232.

Dadashpoor, H., \& Alidadi, M. (2017). Towards decentralization: Spatial changes of employment and population in Tehran Metropolitan Region, Iran. Applied Geography, 85, 51-61. 
Dadashpoor, H., \& Nateghi, M. (2017). Simulating spatial pattern of urban growth using GIS-based SLEUTH model: a case study of eastern corridor of Tehran metropolitan region. Iran. Environment, Development, and Sustainability, 19(2), 527-547.

Dadashpoor, H., \& Salarian, F. (2020). Urban sprawl on natural lands: Analyzing and predicting the trend of land-use changes and sprawl in Mazandaran city region. Iran. Environment, Development, and Sustainability, 22(2), 593-614.

Deng, X., \& Li, Z. (2016). A review of historical trajectories and spatially explicit scenarios of land-use and land-cover changes in China. Journal of Land Use Science, 11(6), 709-724.

Geng, B., Zheng, X., \& Fu, M. (2017). Scenario analysis of sustainable intensive land use based on SD model. Sustainable Cities and Society, 29, 193-202.

Goodarzi, M. S., Sakieh, Y., \& Navardi, S. (2017). Scenario-based urban growth allocation in a rapidly developing area: a modeling approach for sustainability analysis of an urban-coastal coupled system. Environment, Development, and Sustainability, 19(3), 1103-1126.

Haghani, A., Lee, S. Y., \& Byun, J. H. (2003). A system dynamics approach to land use/transportation system performance modeling Part I: Methodology. Journal of Advanced Transportation, 37(1), $1-41$.

Han, H., Yang, C., \& Song, J. (2015). Scenario Simulation and the Prediction of Land Use and Land Cover Change in Beijing. China. Sustainability, 7(4), 4260-4279.

Henareh Khalyani, A., Mayer, A. L., Falkowski, M. J., \& Muralidharan, D. (2013). Deforestation and landscape structure changes related to socioeconomic dynamics and climate change in Zagros forests. Journal of Land Use Science, 8(3), 321-340.

Henríquez-Dole, L., Usón, T. J., Vicuña, S., Henríquez, C., Gironás, J., \& Meza, F. (2018). Integrating strategic land use planning in the construction of future land use scenarios and its performance: The Maipo River Basin. Chile. Land Use Policy, 78(June), 353-366.

Hosseinali, F., Alesheikh, A. A., \& Nourian, F. (2013). Agent-based modeling of urban land-use development, case study: Simulating future scenarios of Qazvin city. Cities, 31, 105-113.

Iran Department of Environment. (2015). Iran's third national communication to UNFCCC. Tehran, Iran. Retrieved from www.doe.ir.

Koomen, E., Koekoek, A., \& Dijk, E. (2011). Simulating Land-use Change in a Regional Planning Context. Applied Spatial Analysis and Policy, 4(4), 223-247.

$\mathrm{Ku}, \mathrm{C}$.-A. (2016). Incorporating spatial regression model into cellular automata for simulating land-use change. Applied Geography, 69, 1-9.

Lamine, S., Petropoulos, G. P., Singh, S. K., Szabó, S., Bachari, N. E. I., Srivastava, P. K., et al. (2018). Quantifying land use/land cover spatiotemporal landscape pattern dynamics from Hyperion using SVMs classifier and FRAGSTATS $®$. Geocarto international, 33(8), 862-878.

Li, Y. C., \& He, C. Y. (2008). Scenario simulation and forecast of land use/cover in northern China. Chinese Science Bulletin, 53(9), 1401-1412.

Liao, J., Tang, L., Shao, G., Su, X., Chen, D., \& Xu, T. (2016). Environmental Modelling \& Software Incorporation of extended neighborhood mechanisms and its impact on urban land-use cellular automata simulations. Environmental Modelling and Software, 75, 163-175.

Liu, D., Zheng, X., Wang, H., Zhang, C., Li, J., \& Lv, Y. (2018). Interoperable scenario simulation of land-use policy for Beijing-Tianjin-Hebei region, China. Land Use Policy, 75, 155-165.

Liu, M., Hu, Y., Zhang, W., Zhu, J., Chen, H., \& Xi, F. (2011). Application of land-use change model in guiding regional planning: A case study in Hun-Taizi River watershed. Northeast China. Chinese Geographical Science, 21(5), 609-618.

Liu, X., Liang, X., Li, X., Xu, X., Ou, J., Chen, Y., \& Pei, F. (2017). A future land use simulation model (FLUS) for simulating multiple land-use scenarios by coupling human and natural effects. Landscape and Urban Planning, 168(October), 94-116.

Liu, Y., Batty, M., Wang, S., \& Corcoran, J. (2019). Modelling urban change with cellular automata: Contemporary issues and future research directions. Progress in Human Geography. https://doi. org/10.1177/0309132519895305.

Liu, Y., \& Feng, Y. (2012). A Logistic Based Cellular Automata Model for Continuous Urban Growth Simulation: A Case Study of the Gold Coast City, Australia. In A. J. Heppenstall, A. T. Crooks, L. M. See, \& M. Batty (Eds.), Agent-Based Models of Geographical Systems (pp. 643-662). NewYork: Springer.

Luo, J., \& Wei, Y. H. D. (2009). Modeling spatial variations of urban growth patterns in Chinese cities: The case of Nanjing. Landscape and Urban Planning, 91(2), 51-64.

Mahmoodzadeh, H., \& Khoshroy, G. (2015). Application of Logistic regression in Urban Development Modeling: The case study of Bonab urban region. Motaleate Shahri, 4(14), 31-46. (In Persian).

Maimaitijiang, M., Ghulama, A., Onésimo Sandoval, J. S., \& Maimaitiyiming, M. (2015). Drivers of land cover and land-use changes in the St. Louis metropolitan area over the past 40 years 
characterized by remote sensing and census population data. International Journal of Applied Earth Observation and Geoinformation, 35, 161-174.

Mancosu, E., Gago-Silva, A., Barbosa, A., de Bono, A., Ivanov, E., Lehmann, A., \& Fons, J. (2015). Future land-use change scenarios for the Black Sea catchment. Environmental Science and Policy, 46, 26-36.

Moein, M., Asgarian, A., Sakieh, Y., \& Soffianian, A. (2018). Scenario-based analysis of land-use competition in central Iran: Finding the trade-off between urban growth patterns and agricultural productivity. Sustainable Cities and Society, 39, 557-567.

Puertas, O. L., Henríquez, C., \& Meza, F. J. (2014). Assessing spatial dynamics of urban growth using an integrated land-use model. Application in Santiago Metropolitan Area, 2010-2045. Land Use Policy, 38, 415-425.

Rounsevell, M. D. A., Reginster, I., Araújo, M. B., Carter, T. R., Dendoncker, N., Ewert, F., \& Tuck, G. (2006). A coherent set of future land-use change scenarios for Europe. Agriculture, Ecosystems, and Environment, 114(1), 57-68.

Sakieh, Y., Amiri, B. J., Danekar, A., Feghhi, J., \& Dezhkam, S. (2015). Simulating urban expansion and scenario prediction using a cellular automata urban growth model, SLEUTH, through a case study of Karaj City. Iran. Journal of Housing and the Built Environment, 30(4), 591-611.

Senes, G., \& Toccolini, A. (1998). Sustainable land-use planning in protected rural areas in Italy. Landscape and Urban Planning, 41(2), 107-117.

Shafizadeh-Moghadam, H., Asghari, A., Taleai, M., Helbich, M., \& Tayyebi, A. (2017a). Sensitivity analysis and accuracy assessment of the land transformation model using cellular automata. GIScience \& Remote Sensing, 54(5), 639-656.

Shafizadeh-Moghadam, H., Asghari, A., Tayyebi, A., \& Taleai, M. (2017b). Coupling machine learning, tree-based, and statistical models with cellular automata to simulate urban growth. Computers, Environment and Urban Systems, 64, 297-308.

Silva, E. A., \& Clarke, K. C. (2005). Complexity, emergence, and cellular urban models: Lessons learned from applying Sleuth to two Portuguese metropolitan areas. European Planning Studies, 13(1), 93-115.

Statistical center of Iran. (1986-2016). General census of population and housing. Retrieved from www. amar.org.

Sun, P., Xu, Y., Yu, Z., Liu, Q., Xie, B., \& Liu, J. (2016). Scenario simulation and landscape pattern dynamic changes of land use in the Poverty Belt around Beijing and Tianjin: A case study of Zhangjiakou city, Hebei Province. Journal of Geographical Sciences, 26(3), 272-296.

Sun, X., Yue, T., \& Fan, Z. (2012). Scenarios of changes in the spatial pattern of land use in China. Procedia Environmental Sciences, 13, 590-597.

Verburg, P. H., Rounsevell, M. D. A., \& Veldkamp, A. (2006). Scenario-based studies of future land use in Europe. Agriculture, Ecosystems \& Environment, 114(1), 1-6.

Verburg, P. H., Soepboer, W., Veldkamp, A., Limpiada, R., Espaldon, V., \& Mastura, S. S. A. (2002). Modeling the spatial dynamics of regional land use: The CLUE-S model. Environmental Management, 30(3), 391-405.

Walsh, S. J., Entwisle, B., Rindfuss, R. R., \& Page, P. H. (2006). Spatial simulation modeling of land use/ land cover change scenarios in northeastern Thailand: A cellular automata approach. Journal of Land Use Science, 1(1), 5-28.

Wu, Q., Li, H. Q., Wang, R. S., Paulussen, J., He, Y., Wang, M., \& Wang, Z. (2006). Monitoring and predicting land use change in Beijing using remote sensing and GIS. Landscape and urban planning, 78(4), 322-333.

Yang, X., Chen, R., \& Zheng, X. Q. (2016). Simulating land-use change by integrating ANN-CA model and landscape pattern indices. Geomatics, Natural Hazards, and Risk, 7(3), 918-932.

Yang, X., \& Lo, C. P. (2003). Modeling urban growth and landscape changes in the Atlanta metropolitan area. International Journal of Geographical Information Science, 17(5), 463-488.

Zarei, A., Dadashpoor, H., \& Amini, M. (2016). Determination of the optimal land-use allocation pattern in Nowshahr County, Northern Iran. Environment, Development, and Sustainability, 18(1), 37-56.

Publisher's Note Springer Nature remains neutral with regard to jurisdictional claims in published maps and institutional affiliations. 